\title{
Efficacy and safety of the pars plana clip in the Ahmed valve device inserted via the pars plana in patients with refractory glaucoma
}

This article was published in the following Dove Press journal:

Clinical Ophthalmology

4 May 2010

Number of times this article has been viewed

\author{
Manuel Diaz-Llopis 1,2,3 \\ David Salom ${ }^{1,3}$ \\ Salvador García-Delpech 1,2,3 \\ Patricia Udaondo ${ }^{1,3}$ \\ Jose Maria Millan ${ }^{3,5}$ \\ J Fernando Arevalo 6 \\ 'Department of Ophthalmology, \\ La Fe University Hospital of Valencia, \\ Valencia, Spain; ${ }^{2}$ Department of \\ Ophthalmology of the Valencia \\ University, Valencia, Spain; ${ }^{3}$ Biomedical \\ Network Research Centre on Rare \\ Diseases (CIBERER), Valencia, Spain; \\ ${ }^{4}$ Catholic University San Vicente \\ Martir, Valencia, Spain; ${ }^{5}$ Department \\ of Genetics, La Fe University Hospital \\ of Valencia, Valencia, Spain; ${ }^{6}$ Clinica \\ Oftalmologica Centro Caracas, Retina \\ and VItreous Service, Caracas, DC, \\ Venezuela
}

Correspondence: Manuel Diaz-Llopis Avenida Campanar 21, 46009 Valencia, Spain

Tel +34666530085

Fax +34963606848

Email maunel.diaz@uv.es
Purpose: To evaluate the efficacy and safety of the pars plana clip (PPC) in the Ahmed valve tube inserted via the pars plana in patients with secondary refractory glaucomas.

Methods: Prospective and interventional case series that included 10 patients with secondary refractory glaucoma. The pars plana vitrectomy and the implant of the modified tube were performed during the same surgery. Control of intraocular pressure (IOP) and the development of intra- and postoperative complications were evaluated during the follow-up.

Results: Follow-up time was twelve months in all the patients. Control of IOP was achieved in $90 \%$ of patients, and $70 \%$ needed no antiglaucoma treatment. The complications that occurred were transient hypotony in three cases, choroidal detachment in two cases, and one case of intraocular hemorrhage. No case of tube extrusion or tube kink was observed.

Conclusions: Our data suggests that implantation of the Ahmed tube modified with the PPC via the pars plana is safe and effective in patients with secondary refractory glaucomas.

Keywords: pars plana clip, Ahmed valve, refractory glaucoma, pars plana vitrectomy

\section{Introduction}

Different types of drainage devices for the treatment of glaucoma have been evaluated for decades and such devices have been classified into two types: nonvalvular (Molteno, Baerveldt) and valvular (Ahmed). The latter only allows the flow of aqueous humor when the intraocular pressure exceeds a certain value, thus avoiding possible extreme postoperative hypotony; their success rates are similar to those of other valvular devices.

All valvular devices present a common characteristic; their drainage tubes are typically implanted through the corneal limbus into the anterior chamber. Efficacy in the control of intraocular pressure goes from $75 \%$ to $90 \%$ and complications develop in $30 \%$ or $40 \%$ of patients. ${ }^{1-5}$ The most typical complications are: hyphema; endothelial decompensation; obstruction or extrusion of the drainage tube; conjunctival erosion with exposure of the tube; iritis; malignant glaucoma; pupillary block; and choroidal detachments, which are more frequent when there are anatomical alterations of the anterior segment.

As an alternative to implantation of drainage tubes in the anterior chamber, some ophthalmologists prefer to insert the drainage tube through the pars plana and leave it in the vitreous cavity thus avoiding the numerous complications resulting from the presence of the tube in the anterior chamber. ${ }^{6-12}$ The percentage of successful results is normally around $90 \%$, which is similar to that reported in studies on tube implants in the anterior chamber. Tube implantation in the vitreous chamber is not 
exempt from complications, amongst which are acute postoperative hypotony, ${ }^{9}$ transient choroidal detachment, ${ }^{9}$ vitreous hemorrhage, retinal detachment, ${ }^{7,8}$ extrusion of the tube, or obstruction through kinking at the sclerectomy site. ${ }^{13}$ No study has described the typical complications of tube implantation in the anterior chamber, such as corneal decompensation, hyphaema, exposure of the tube by conjunctival erosion, iritis, or blocked pupils.

To avoid kinking and extrusion of the tube when it is implanted via the pars plana, two devices were developed that allowed the tube to be anchored to the sclera and at the same time to be given a suitable angle. The first was the Hoffman elbow which was used to modify the Baerveldet nonvalvular drainage device; it has been evaluated in two previous studies. ${ }^{14,15}$ In the case of Ahmed's glaucoma valve, the pars plana clip (PPC) was developed as a modification; as far as we know it has only been evaluated in one previous study. ${ }^{16}$

The aim of our study was to evaluate the efficacy and safety of the PPC in controlling intraocular pressure (IOP) when performing a vitrectomy and implant of an Ahmed's valve drainage tube, via the pars plana, during the same surgical procedure in patients with secondary refractory glaucoma.

\section{Methods}

The patients included in this prospective interventionist study were selected by the Ophthalmology Service of the University General Hospital of Valencia. The patients presented with secondary glaucoma refractory to medical treatment or glaucoma surgery (trabeculectomy, cryocyclodestruction). All the participants were aged over 18 years and gave their informed consent before being included in the study.

The following data were collected and analyzed: demographic characteristics of the patients (age, gender); type of glaucoma; together with medical treatment and previous surgery. The intraocular pressure was measured by Goldman's tonometry. Surgery was defined as "successful" when the IOP was $\leq 21 \mathrm{mmHg}$ without the help of any antiglaucoma medication. Data was also collected for any antiglaucoma treatment necessary at each visit, the need of further surgery or complications developed during surgery, during the follow-up period. The patients' followup examinations were performed at 1 day, 1 week, 1 month, 3 months, 6 months, and 1 year after surgery.

The Wilcoxon nonparametrical significance test for paired data was used to analyze the difference between preoperative and postoperative IOP, taking $P$ as 0.05 or under to consider the differences as statistically significant.

\section{Surgical procedure}

All the patients received pars plana vitrectomy and implant of the modified Ahmed valve in the same standard 3-port surgery. Special attention was paid to eliminating the anterior vitreous during surgery. Cataract surgery was also performed on phakic patients in the same surgical act.

All the patients received model FP7 flexible silicone Ahmed valves (New World Medical, Rancho Cucamonga, CA, USA) modified with the PPC. This valve consists of a $16 \times 13 \mathrm{~mm}$ episcleral drainage plate and a tube with an external diameter of $0.64 \mathrm{~mm}$. The PPC is a silicone device with an entry orifice in the upper face and an exit orifice in the lower face which the silicone tube passes through.

Once the vitrectomy had been performed the valve was purged with saline serum and sutured at $15 \mathrm{~mm}$ from the corneal limbus, with 5.0 nylon in either of the two superior quadrants. Then the drainage tube was inserted through the PPC and next through one of the sclerectomies used for the vitrectomy at $3.5 \mathrm{~mm}$ from the corneal limbus; after that, 5 or $6 \mathrm{~mm}$ of the tube was introduced into the eye, making sure it was visible through the dilated pupil. The PPC was sutured to the sclera with 8.0 nylon, over which a patch of bovine pericardium Tutopatch (Tutogen Medical, Bavaria, Germany) was also sutured with 8.0 nylon. Once the surgery was complete everything was covered with the conjunctiva (Figures 1-4).

\section{Results}

Ten modified Ahmed valves were implanted through the pars plana in ten patients with secondary refractory glaucoma during the year the study lasted. All the patients received twelve months' follow-up and none of the patients initially included in the study was excluded from the results analyses.

\section{Patient demographics}

Demographic and preoperative data are shown in Table 1. The average age of the patients was 54.4 years. All the patients presented with chronic glaucoma refractory to medical treatment or surgery (Trabeculectomy, cyclocoagulation). Three patients had neovascular glaucoma in which the ischemic process had been controlled previously by means of pan photocoagulation by argon laser or transscleral pan cryocoagulation. Three patients had secondary glaucoma due to uveitis and were receiving chronic corticosteroid treatment (one of them had an intraocular fluocinolone deposit). Two patients presented with secondary traumatic glaucoma; and a further two patients presented with secondary glaucoma after penetrating keratoplasty.

Implantation via the pars plana was chosen for the two patients with secondary traumatic glaucoma because of 


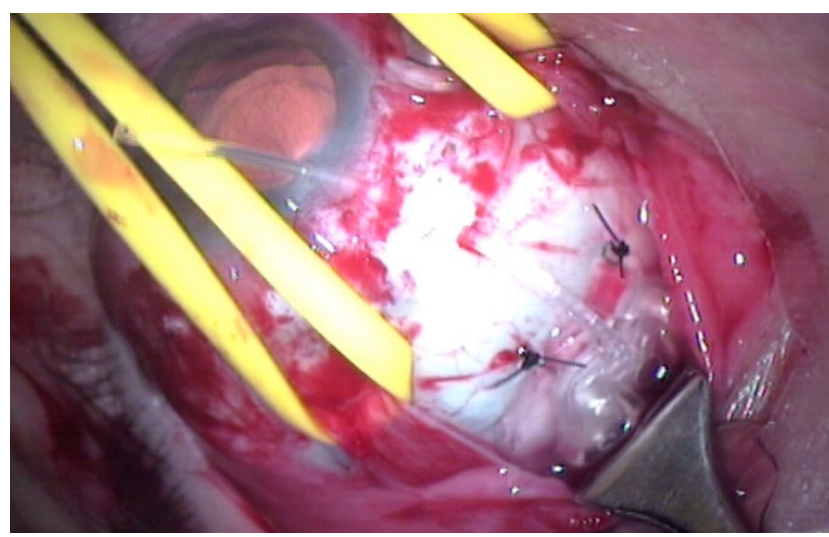

Figure I Once the vitrectomy had been performed the Ahmed's FP7 valve (NewWorld Medical, Ranch Cucamoga, CA, USA) was purged with saline serum and sutured $15 \mathrm{~mm}$ from the corneal limbus with 5.0 nylon in either of the two superior quadrants.

repeated anterior chamber surgery, although they did not present with secondary angle closure. Six of the patients were pseudophakic, two were aphakic, and two were phakic before surgery. Two of the patients, one with uveitis secondary glaucoma and the other with secondary traumatic glaucoma, had previously undergone a partial vitrectomy which was completed at the same time as the implant of the valves.

\section{Intraocular pressure results}

The mean preoperative IOP was $32 \mathrm{mmHg}$ and the mean postoperative IOP at one year was $16 \mathrm{mmHg}$ with significant statistical differences $(P=0.001)$ (Table 1). We were able to control IOP in 9 out of 10 of the patients (90\%). Seven patients $(70 \%)$ did not require antiglaucoma medication to control IOP. Two of the three patients who needed additional medication only required topical treatment (Timolol), the remaining patient needed three topical drugs (Dorzolamide, Brimonidine and Bimatoprost) resulting in one uncontrolled IOP of $24 \mathrm{mmHg}$.

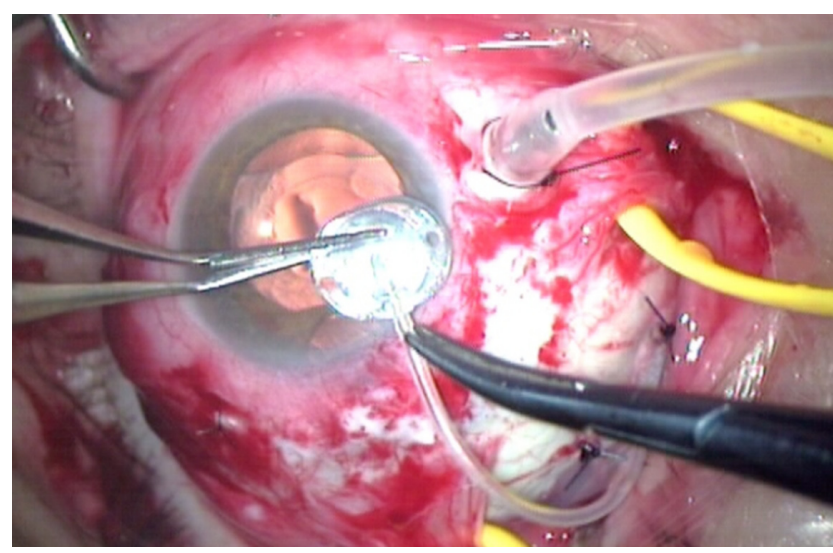

Figure 2 The pars plana clip is a silicone device with an entry orifice in the upper face and an exit orifice in the lower face which the silicone tube passes through.

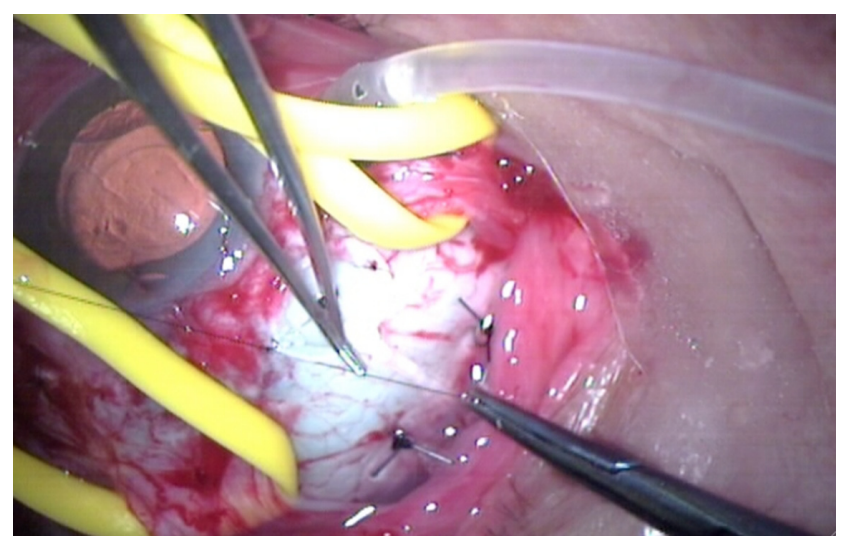

Figure 3 Five or six $\mathrm{mm}$ of the drainage tube was introduced into the eye through one of the sclerectomies used for the vitrectomy at $3.5 \mathrm{~mm}$ from the corneal limbus, making sure it was visible through the dilated pupil. The PPC was then sutured to the sclera with 8.0 nylon.

\section{Complications}

The majority of the complications were transitory; notable among these were three cases of transitory postoperative hypotony (30\%), two cases of choroidal detachment $(20 \%)$, two cases of transitory ocular hypertension (20\%), and one case of vitreous hemorrhage (10\%) which was the same patient who suffered a total retinal detachment.

The cases of transitory hypertension were due to: the presence of a vitreous strand that was obstructing the entry of the tube in one case; and to the development of a perivalvular fibrosis in the other. In both cases we obtained an instantaneous resolution by using YAG laser on the vitreous bridle and by needling together with $0.2 \%$ mitomycin-C.

It is important to emphasize that there were no cases of conjunctival erosion from exposure of the PPC, extrusion of the drainage tube or its obstruction due to kinking. Neither were complications, such as corneal decompensation or hyphema observed.

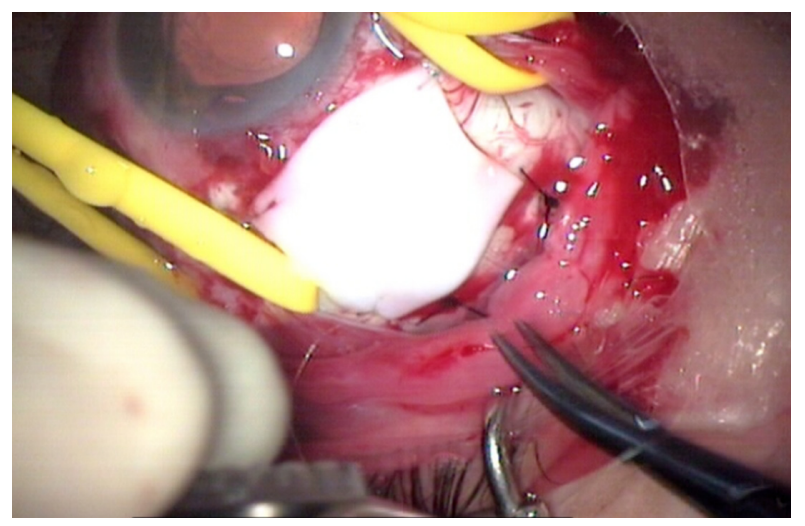

Figure $4 \mathrm{~A}$ patch of bovine pericardium Tutopatch (Tutogen Medical) was sutured over the pars plana clip with 8.0 nylon, and everything was then covered with the conjunctiva. 
Table I Summary of results

\begin{tabular}{|c|c|c|c|c|c|c|}
\hline Patient no & Diagnosis & Eye & Age & Preoperative IOP & Postoperative IOP & Complications \\
\hline \multirow[t]{3}{*}{$\mathrm{I}$} & Neovascular & $\mathrm{R}$ & 72 & $40 \mathrm{mmHg}$ & $24 \mathrm{mmHg}$ & Transitory hypotony \\
\hline & & & & & & Vitreous hemorrhage \\
\hline & & & & & & Choroidal detachment \\
\hline 2 & Neovascular & $\mathrm{L}$ & 64 & $35 \mathrm{mmHg}$ & $20 \mathrm{mmHg}$ & Transitory hypertension \\
\hline \multirow[t]{2}{*}{3} & Keratoplasty & $\mathrm{L}$ & 59 & $26 \mathrm{mmHg}$ & $14 \mathrm{mmHg}$ & Transitory hypotony \\
\hline & & & & & & Choroidal detachment \\
\hline 4 & Traumatism & $\mathrm{L}$ & 44 & $30 \mathrm{mmHg}$ & $12 \mathrm{mmHg}$ & \\
\hline 5 & Neovascular & $\mathrm{R}$ & 70 & $38 \mathrm{mmHg}$ & $18 \mathrm{mmHg}$ & \\
\hline 6 & Uveitis & $\mathrm{R}$ & 36 & $24 \mathrm{mmHg}$ & $12 \mathrm{mmHg}$ & Transitory hypotony \\
\hline 7 & Uveitis & $\mathrm{L}$ & 54 & $34 \mathrm{mmHg}$ & $13 \mathrm{mmHg}$ & Transitory hypertension \\
\hline 8 & Keratoplasty & $\mathrm{R}$ & 62 & $32 \mathrm{mmHg}$ & $15 \mathrm{mmHg}$ & \\
\hline 9 & Traumatism & $\mathrm{L}$ & 49 & $32 \mathrm{mmHg}$ & $14 \mathrm{mmHg}$ & \\
\hline 10 & Uveitis & $\mathrm{R}$ & 34 & $29 \mathrm{mmHg}$ & $18 \mathrm{mmHg}$ & \\
\hline
\end{tabular}

\section{Discussion}

Over the years, therapeutic alternatives have been developed for patients with glaucoma refractory to conventional therapies, such as, treatment with antimetabolites in trabeculectomy or performing different cyclodestructive procedures. These alternatives have not managed to control IOP in all patients and they put the patient at risk of developing potentially severe complications.

Development of drainage implants to create an alternative pathway for the exit of aqueous humor have been evolving since the 1960's providing better success rates and a diminishing frequency of complications. From the beginning, the drainage tubes of these valvular implants were placed in the anterior chamber of the eye. The presence of a tube in the anterior chamber generates a great number of complications, among which endothelial decompensation and hyphema are the most serious. These complications were more frequent in cases of complex glaucoma, such as neovascular glaucomas after keratoplasty, uveitis or traumatism as these usually develop a closing angle of $360^{\circ}$.

The technique of implanting the drainage tubes in the vitreous chamber, via the pars plana was developed and provided a solution to these cases. Studies in the literature using this technique focused on glaucomas with previous shallow anterior chamber, extensive angular closing, neovascular glaucomas, and glaucomas with associated vitreoretinal pathology. ${ }^{11,12,17}$ The frequency of success varied, depending on the study, from $75 \%$ to $90 \%$. New complications also appeared with this technique, two of which should be described: the first involves the extrusion of the tube due to deficient fixation to the sclera; the second consists of the secondary obstruction of the tube by kinking caused by the force vectors generated at the sclerectomy site.
Two studies were recently published that evaluate devices in conjunction with drainage tubes that diminish the incidence of these complications. The first, by Lutrull evaluated Hoffman's elbow for implanting Baerveldt's valves. ${ }^{18}$ Subsequently the PPC was developed which makes it possible to anchor an Ahmed's valve tube to the sclera and give it the suitable angle for insertion through the pars plana into the vitreous chamber in the same act. Schlote was the first, and only one to our knowledge, to evaluate its efficiency, reporting successful results of around $90 \% .{ }^{16}$ No cases were observed evidencing the extrusion of the tube or its obstruction by kinking. We consider, however, that there are two debatable factors in this work: the first is that at least three months elapsed between the time of the vitrectomy and the valvular implant; and the second is the use of polypropylene Ahmed valves.

In the present study we modified these factors for the reasons detailed below. In our study, the vitrectomy was performed during the same surgery for the implant of an Ahmed's valve, with a view to: optimizing the resources; lessening patient stress associated with further surgery; and controlling the patients' earlier ocular hypertension. We believe that delay in the treatment of patients with uncontrolled glaucomas can involve serious damage to the optical nerve. Moreover, the implant of Ahmed valves at the level of the pars plana should not be limited exclusively to non-phakic or pseudophakic patients; given that phakic patients can undergo cataract surgery during the same surgical procedure, as was achieved in two of our patients. We chose silicone valves since polypropylene valves have proved to be a major cause of inflammation. ${ }^{19}$

In this study we implanted ten PPC-modified Ahmed valves via the pars plana in ten patients with secondary angle 
closure glaucoma, refractory to medical treatment and/or conventional filtered surgery. We were able to control IOP in $90 \%$ of patients. No additional antiglaucoma medication was necessary in $70 \%$ of patients to control IOP and IOP control only proved unsuccessful for $10 \%$ of patients in spite of the associated antiglaucoma medication.

We observed none of the typical complications that have occurred with the implant of tubes via the pars plana in the past resulting from of either extrusion of the tube or its obstruction due to kinking at the entry site to the eye. This is because the PPC gives the tube a firmer anchorage on the sclera and due to a stable entry angle. Neither were conjunctival erosions with exposure of the PPC observed, possibly because it was covered by a pericardium patch. Three cases of transitory postoperative hypotony were observed, one of which was complicated by a choroidal detachment and postoperative vitreous hemorrhage, which resulted in a total retinal detachment. This patient presented with an advanced neovascular glaucoma secondary to an inadequately controlled diabetic retinopathy. The patient rejected further surgery after being informed of the therapeutic alternatives. This case demonstrates that patients can develop serious complications with this surgical technique and that it is essential to confront each case individually. We propose three possible methods to prevent postoperative hypotony. The first is an intravitreal injection of SF6 or C3f8 gas on completing surgery. The second is the partial occlusion of the tube with an adjustable suture that is released immediately after surgery. The third is the use of pediatric Ahmed valves that present a smaller sized plate and therefore a smaller filtration surface. In our study, two patients developed postoperative hypotony owing to the presence of vitreous at the mouth of the tube resulting in the development of perivalvular fibrosis; this was solved simply and immediately with the use of a YAG laser on the tube and needling together with $0.2 \%$ mitomycin-C.

We believe the implant of Ahmed's valves through the pars plana in patients with secondary closure angle glaucoma is more effective and avoids a considerable number of complications than the implant of valves in the anterior chamber. The combined surgery of vitrectomy and valvular implant does not increase the technical difficulty of the surgery excessively, nor does it involve an increase in the rate of complications. On the other hand, this preliminary study presents certain limitations, such as the relatively short follow-up period, and the low number of participants, which was due to a shortage of patients who complied with the selection criteria. The study design also has certain limitations: ie, being noncomparative and nonrandomized. The need of further studies is warranted in order to establish the long term efficacy and safety of the PPC. However, our data suggest that the use of the PPC for inserting Ahmed's valve tube through the pars plana makes it possible to control the IOP of patients with refractory glaucoma caused by secondary angular closing in a safe and effective way.

In conclusion, this study shows that due to the complexity of some patients' pathological conditions, it is essential to establish globalized surgical strategies, appropriately termed "from pole to pole", that blur the limits of surgical sub-specialties in ophthalmology.

\section{Disclosures}

The authors report no conflicts of interest relevant to this research.

\section{References}

1. Huang MC, Netland PA, Coleman AL, Siegner SW, Moster MR, Hill RA. Intermediate-term clinical experience with the Ahmed Glaucoma Valve implant. Am J Ophthalmol. 1999;127(1):27-33.

2. Tsai JC, Johnson CC, Dietrich MS. The Ahmed shunt versus the Baerveldt shunt for refractory glaucoma: a single-surgeon comparison of outcome. Ophthalmology. 2003;110(9):1814-1821.

3. Freedman J, Rubin B. Molteno implants as a treatment for refractory glaucoma in black patients. Arch Ophthalmol. 1991;109(10):1417-1420.

4. Topouzis F, Coleman AL, Choplin N, et al. Follow-up of the original cohort with the Ahmed glaucoma valve implant. Am J Ophthalmol. 1999;128(2):198-204

5. Nouri-Mahdavi K, Caprioli J. Evaluation of the hypertensive phase after insertion of the Ahmed Glaucoma Valve. Am J Ophthalmol. 2003;136(6):1001-1008.

6. Kaynak S, Tekin NF, Durak I, Berk AT, Saatci AO, Soylev MF. Pars plana vitrectomy with pars plana tube implantation in eyes with intractable glaucoma. Br J Ophthalmol. 1998;82(12):1377-1382.

7. Lloyd MA, Heuer DK, Baerveldt G, et al. Combined Molteno implantation and pars plana vitrectomy for Neovascular glaucomas. Ophthalmology. 1991;98(9):1401-1405.

8. Luttrull JK, Avery RL. Pars plana implant and vitrectomy for treatment of neovascular glaucoma. Retina. 1995;15(5):379-387.

9. Sheppard JD, Shrum KR. Pars plana Molteno implantation in complicated inflammatory glaucoma. Ophthalmic Surg. 1995;26(3): 218-222.

10. Sidoti PA, Mosny AY, Ritterband DC, Seedor JA. Pars plana tube insertion of glaucoma drainage implants and penetrating keratoplasty in patients with coexisting glaucoma and corneal disease. Ophthalmology. 2001;108(6):1050-1058.

11. Smiddy WE, Rubsamen PE, Grajewski A. Vitrectomy for pars plana placement of a glaucoma seton. Ophthalmic Surg. 1994;25(8): $532-535$.

12. Varma R, Heuer DK, Lundy DC, Baerveldt G, Lee PP, Minckler DS. Pars plana Baerveldt tube insertion with vitrectomy in glaucomas associated with pseudophakia and aphakia. Am J Ophthalmol. 1995;119(4):401-407.

13. Rothman RF, Sidoti PA, Gentile RC, et al. Glaucoma drainage tube kink after pars plana insertion. Am J Ophthalmol. 2001;132(3): 413-414.

14. Molteno AC, Straughan JL, Ancker E. Long tube implants in the management of glaucoma. S Afr Med J. 1976;50(27):1062-1066. 
15. Chalam KV, Gandham S, Gupta S, Tripathi BJ, Tripathi RC. Pars plana modified Baerveldt implant versus neodymium:YAG cyclophotocoagulation in the management of neovascular glaucoma. Ophthalmic Surg Lasers. 2002;33(5):383-393.

16. Schlote T, Ziemssen F, Bartz-Schmidt KU. Pars plana-modified Ahmed Glaucoma Valve for treatment of refractory glaucoma: a pilot study. Graefes Arch Clin Exp Ophthalmol. 2006;244(3):336-341.

17. Gandham SB, Costa VP, Katz LJ, et al. Aqueous tube-shunt implantation and pars plana vitrectomy in eyes with refractory glaucoma. Am J Ophthalmol. 1993;116(2):189-195.
18. Luttrull JK, Avery RL, Baerveldt G, Easley KA. Initial experience with pneumatically stented baerveldt implant modified for pars plana insertion for complicated glaucoma. Ophthalmology. 2000;107(1): $143-149$.

19. Ayyala RS, Michelini-Norris B, Flores A, Haller E, Margo CE. Comparison of different biomaterials for glaucoma drainage devices: art 2. Arch Ophthalmol. 2000;118(8):1081-1084.
Clinical Ophthalmology

\section{Publish your work in this journal}

Clinical Ophthalmology is an international, peer-reviewed journal covering all subspecialties within ophthalmology. Key topics include: Optometry; Visual science; Pharmacology and drug therapy in eye diseases; Basic Sciences; Primary and Secondary eye care; Patient Safety and Quality of Care Improvements. This journal is indexed on

\section{Dovepress}

PubMed Central and CAS, and is the official journal of The Society of Clinical Ophthalmology (SCO). The manuscript management system is completely online and includes a very quick and fair peer-review system, which is all easy to use. Visit http://www.dovepress.com/ testimonials.php to read real quotes from published authors. 